\title{
Model and Simulation of Permanent Magnets Synchronous Machine (PMSM) of the Electric Power Supply System (EPS), in Accordance with the Concept of a More Electric Aircraft (MEA)
}

\author{
Lucjan Setlak ${ }^{*}$, Rafat Kowalik ${ }^{1}$
}

${ }^{1}$ Department of Avionics and Control Systems, Polish Air Force Academy, ul. Dywizjonu 303 nr 35, 08-521 Deblin

\begin{abstract}
Based on the mathematical model of synchronous electric machine, basing on permanent magnets, presented in this paper, the key importance of alternator AC power sources in the form of generator (for conventional aircraft) and in the form of integrated unit starter/AC synchronous generator $\mathrm{S} / \mathrm{G} \mathrm{AC}$ (with respect to advanced aircraft concept in the field of more/all electric power MEA/AEA) was highlighted. In addition, through the analysis and selected simulations of the power supply system of a modern aircrafts, sources of onboard electrical energy (synchronous generator, integrated unit starter/AC generator) were located in board autonomic power system ASE (EPS, PES). Key components of this system are the electro-energetic power system EPS and the energo-electronic power system PES. Additionally, the analysis and exemplary simulations of key electricity sources based on mathematical models have contributed to highlighting the main practical applications in line with the trend of a more electric aircraft.
\end{abstract}

\section{Introduction}

Currently, gradually increasing dynamics of changes in the board power supply in modern aviation can be seen, both in the field of civil aircrafts (Airbus, Boeing) for airplanes (A-350XWB, B-787), as well as for military aviation (Lockheed Martin) in terms of aircrafts JSF (Joint Strike Fighter) F-35 and F-22 Raptor. These changes will have a crucial impact on rapidly growing trend in the more electric aircraft. They include in particular the dominant role of advanced systems in the production/processing of AC (Alternating Current) voltage and their basic components (rectifiers, converters, etc.), as well as the EPS (Electric Power System) in the field of DC (synchronous motor or a generator, a DC battery as a source of emergency, whichstores energy, fuel cells, etc.). Referringto the selected issues in terms of power electronics, power electronics associated with advanced power systems PES (Power Electronics Systems) it should be noted that the main components of the system PES, i.e. energyelectronic converters and their key elements, which are multi-pulse rectifiers are classified as so-called on-board autonomous electro-energetic systems ASE.

One of the most significant ASE systems, in addition to electric power systems EPS is a powersystemin the range of PES. Making a preliminary analysis of the dominant role of the on-board power supply voltage AC it should be noted that the power network is based on a generator of high frequency, namely, a Constant Frequency (CF) $400 \mathrm{~Hz}$ (in the case "classical" aircrafts) and Variable Frequency (VF) $390-780 \mathrm{~Hz}$ (in the case of airplanes
"More Electric"). The above analysis includes also a combinationstarter/AC synchronous generator AS/G VF (Alternating Starter/Generator VF), an example of which together with key components of ASE system is ilustrated in the figure below (Fig. 1) [1], [2].

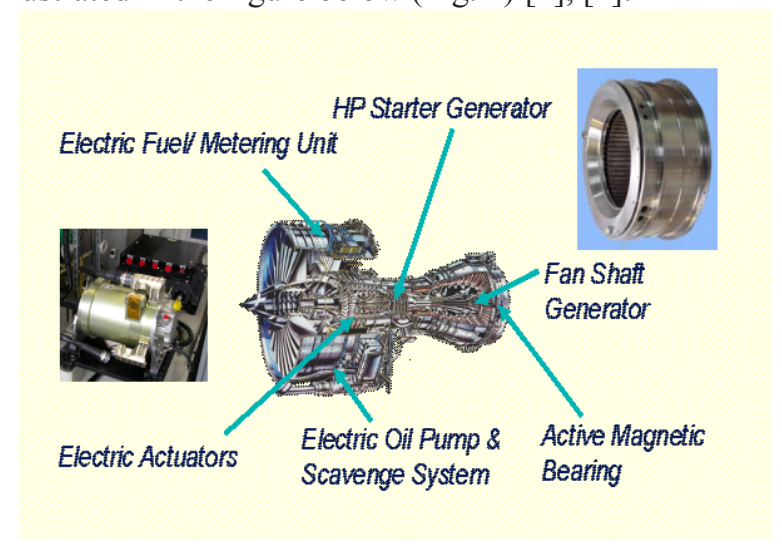

Fig. 1. Example of synchronous 3-phase $A S / G$ VF in the context of MEE (More Electric Engine) [3]

On the modern airplanes there are primarily used treephase synchronous machine (eg. generators) as sources for generating electricity of multiphase alternating current of high power. It should be noted that this kind of electrical machinery PMSM works best during generator operation, that is, in terms of power. This does not mean that they can not operate within the motor, or in terms of starting the engine. However, in this operating range of their properties their operation is much worse. Typically, they are used in electric drive systems, which are

Corresponding author: 1.setlak@wsosp.pl, r.kowalik@wsosp.pl 
required to maintain strict speed of specific systems, devices, etc. when the load changes in a wide range. The further part of the article presents the analysis along with the trend of more electric aircraft based on its main component, which is a 3-phase synchronous generator, serving as the primary source of electricity generation on board of modern aircraft.

\section{Analysis and mathematical model of EPS of a More Electric Aircraft}

Sample analysis was presented on the basis of a key component of EPS system, which is a synchronous generator PMSM with permanent magnets, which is a primary source of power for modern aircrafts complying with the trend of the more electric aircraft MEA, both civilian (Airbus, Boeing), as well as the military (Lockheed Martin) [4], [5]. Power supply of the board network, is done partly through its primary sources (generator, integrated unit starter/generator). The process of starting the engine is realized by a driving turbine and consequently mechanical energy is produced supplied by means of suitable systems to the generator. The task of generator is processing mechanical rotational energy of engine into electrical energy of 3-phase AC voltage, which is then fed to the head rail of autonomous power system ASE in terms of EPS system. It should also be noted that in the case of advanced aircraft in line with the concept of more/all electric aircraft (MEA/AEA), the boot process of electrical unit is realized by means of electrical energy, which is an important advantage of this type of solution.

Taking into account the high complexity of on-board power system EPS and its large load, the most suitable device (a source of electricity production) in the exercise of the function is a synchronous motor PMSM, having a good airworthiness in particular areas of work, autonomous work and robust design. Furthermore, the use of such a generator in aviation allows to produce not only 3-phase AC voltage, but also to obtain from it at least twice the electric power, comparing it with a DC generator in terms similar parameters, which are the size and weight. This property decided primarily about the application of this type of generator as a source of electricity generation on modern aircrafts because of the alternating voltage waveform generated by the 3-phase air generators. Sometimes colloquially they are referred to as alternators, but the term refers primarily to the sources of electricity generation in the automotive industry. The construction and method of cooperation of synchronous generator PMSM with on-board electrical system is presented later in this article. The following figures illustrate a simplified internal structure of the 3phase generator PMSM (Fig. 2) and the general scheme of operation of the rectifier system (Fig. 3) [6].

In the 3-phase AC generator in terms of its architecture, in analogy to DC generator, you can extract the wound stationary stator, inside which a rotor rotates. Stator windings placed in slots are the same three phase coils, spatially shifted by an angle $\frac{2}{3} \pi \mathrm{rad}$. This kind of solution for the spatial distribution of the winding was obtained by placing the sides of each coil of one phase winding in the opposite the slots.

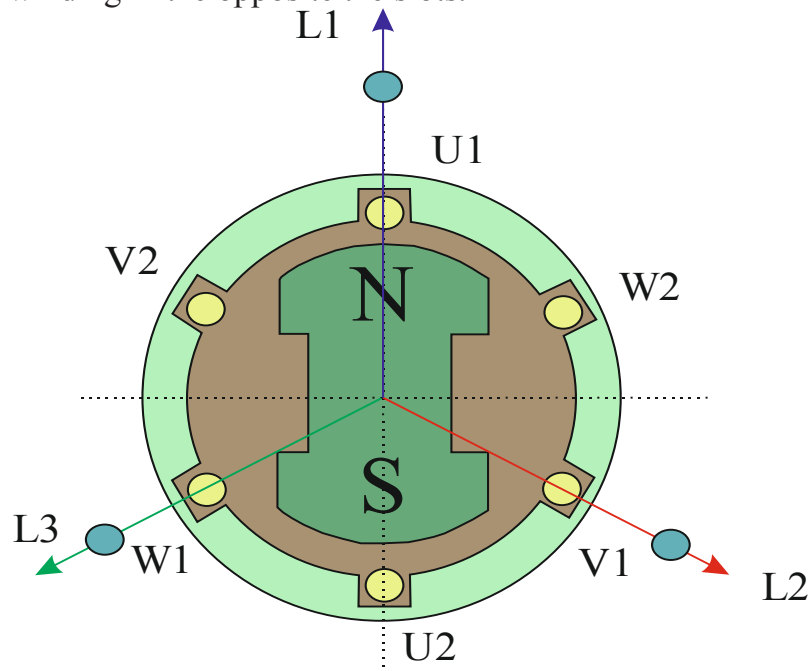

Fig. 2. The general structure of the synchronous generator PMSM

The source of the static magnetic field in a three-phase AC generator, as in the single-phase generator, is the rotor rotating at a constant angular speed speed $\omega$ within the three phases of wound stationary stator. In turn, the rotating constant magnetic field of the rotor during its movement induces in the windings of the stator phase voltages, which are called symmetric because they have the same amplitude and frequency, and differ only in phase-angle specified by spatial distribution of the phase windings on the stator of the generator.

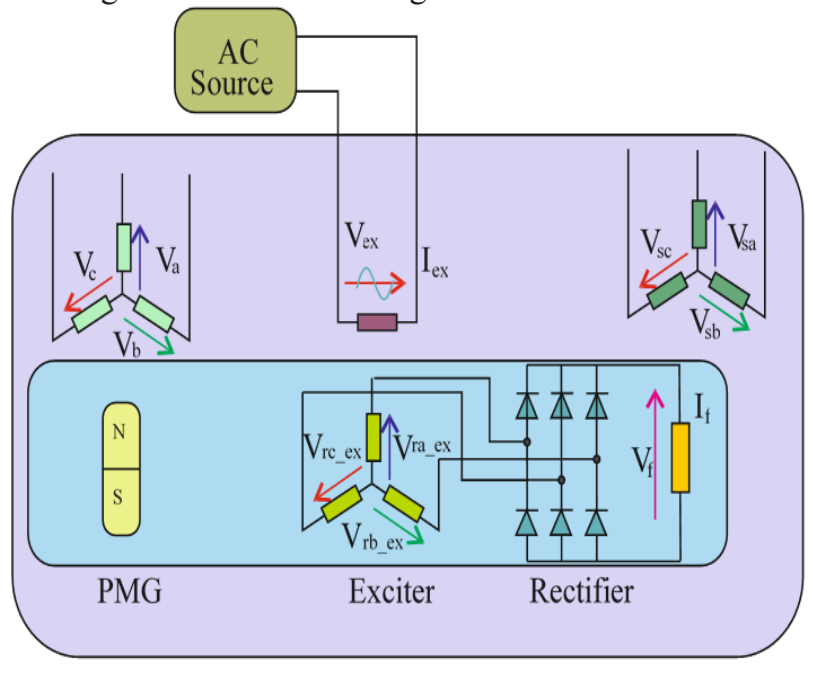

Fig. 3. The general functional diagram of the rectifier system used board of modern aircrafts

It should be noted that in terms of starter (motor) work, suitable torque must be made, which differs significantly from the load torque for the process to start the main engine of the generator. Therefore, the stator winding excitation is powered by $\mathrm{AC}$, which via a transformer causes induction of the electromagnetic field inside the exciter, so it is possible to determine whether the rotor is rotating (working) whether it is permanent (idle).

Produced by this process, the electromagnetic field induces an AC voltage in exciter stator, which in turn by 
means of a rectifier is supplied to the synchronous generator rotor PMSM. Changing the frequency of AC voltage causes that the exciter is powered from the control of operation of the generator. In addition, the power output of the generator for the $\mathrm{AC}$ produces a torque which is delivered to the main rotor and the mechanical output power is obtained by rotating rotor. The Fig. 3 shows the wiring diagram of the synchronous machine PMSM on the field of motoring. It can be seen that the outputs of the synchronous machine are not connected, and the voltage of generator excitation is provided by an external source.

The equation describing the electrical phenomena in a synchronous generator PMSM in a $d-q$ in the case of three-phase power system, with the included transformation of the position of the rotor $d-q$ was expressed by the following mathematical relationship (designation used in the mathematical analysis is explained in Table 1).

The voltage in the position of the $d$ [7], [8], [9]

$$
V_{d}=R_{s} I_{d}+\frac{d \psi_{d}}{d t}-\omega \psi_{q}
$$

The voltage in the position of the $q$

$$
V_{q}=R_{s} I_{q}+\frac{d \psi_{q}}{d t}-\omega \psi_{d}
$$

The voltage dependent on the frequency change

$$
V_{f}=R_{f} I_{f}+\frac{d \psi_{f}}{d t}
$$

Where the stream $\psi$ produced in the synchronous generator in the position $d$ is defined as

$$
\psi_{d}=L_{d} I_{d}+M_{s f} I_{f}
$$

For position to the $q$

$$
\psi_{q}=L_{q} I_{q}
$$

and

$$
\psi_{f}=L_{f} I_{f}+\frac{3}{2} M_{s f} I_{d}
$$

A further mathematical analysis of the electric model of PMSM generator includes saturation resulting in the system. Therefore, depending on the inductance value, the saturation rate $K_{\text {sat }}$ can be written as

$$
\begin{gathered}
L_{d}=K_{s a t} L_{m d}+L_{c d} \\
L_{q}=K_{s a t} L_{m q}+L_{c q} \\
L_{f}=K_{s a t} L_{m f}+L_{c f} \\
M_{s f}=K_{s a t} M
\end{gathered}
$$

where $L, L_{m}$ and $L_{c}$ denote the inductance, magnetic inductance and inductance losses of PMSM generator respectively.
It should also be noted that the ratio of saturation occurring in a PMSM generator is determined by determining the balance of amplitude magnetizing current, defined as

$$
I_{m}=\sqrt{\left(I_{f}+\left(\frac{L_{m d}}{M}\right) I_{d}\right)^{2}+\left(\left(\frac{L_{m q}}{M}\right) I_{q}\right)^{2}}
$$

where $I_{m}$ is equivalent of the excitation current, obtained on a generator stator in a $d-q$ and on the other side of excitation circuit.

The movement of the motor (turbine) is described by the equation

$$
J \frac{d \omega}{d t}+f \omega=p\left(T_{e}+T_{L}\right)
$$

where $\omega$ is a rotor speed of the generator; $p$ is the number of poles in the PMSG; $\mathrm{J}$ moment of inertia; $T_{e}$ the electromagnetic torque of the synchronous machine rotor designated in a $d-q$.

This value can be determined from the equation

$$
T_{e}=\frac{3}{2} p\left(M_{s f} I_{f} I_{q}+\left(L_{d}-L_{q}\right) I_{d} I_{q}\right)
$$

As it regards the moment $T_{L}$, it may be determined depending on the rotational speed. Moreover, the technical solutions of synchronous generator moment variation $T_{L}$ is small in the time interval, therefore it can be assumed that a negligible effect on the dynamics of mechanical processes occurring in the generator it can be in further considerations omitted. Therefore, non-linear equation of state of synchronous generator in a $d-q$ may be defined as

$$
D=L_{d} L_{f}-\frac{3}{2} M_{s f}^{2}
$$

Complete (full) mathematical models, defining the status of work in the PMSM generator can be determined by performing the transformation of equations associated with the rotor (3) - (6). All possible differential equations describing the electrical phenomena in the electrical system, which is the generator are as follows [10], [11], [12] 


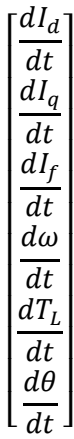

$$
\begin{aligned}
& {\left[\begin{array}{cccccc}
-\frac{R_{s} L_{f}}{D} & \frac{L_{q} L_{f} \omega}{D} & \frac{R_{f} M_{s f}}{D} & 0 & 0 & 0 \\
-\frac{L_{d}}{L_{q}} \omega & -\frac{R_{s}}{L_{q}} & -\frac{M_{s f}}{L_{q}} \omega & 0 & 0 & 0 \\
\frac{3 R_{s} M_{s f}}{2 D} & -\frac{3 L_{q} M_{s f}}{2 D} \omega & -\frac{R_{f} L_{d}}{D} & 0 & 0 & 0 \\
\frac{3 p^{2}}{2 J}\left(L_{d}-L_{q}\right) I_{q} & \frac{3 p^{2}}{2 J} M_{s f} I_{f} & 0 & -\frac{f}{J} & \frac{p}{J} & 0 \\
0 & 0 & 0 & 0 & 0 & 0 \\
0 & 0 & 0 & 1 & 0 & 0
\end{array}\right]} \\
& {\left[\begin{array}{c}
I_{d} \\
I_{q} \\
I_{f} \\
\omega \\
T_{L} \\
\theta
\end{array}\right]+\left[\begin{array}{ccc}
\frac{L_{f}}{D} & 0 & -\frac{M_{s f}}{D} \\
0 & 0 & \frac{1}{L_{q}} \\
3 M_{s f} & 0 & \frac{L_{d}}{D} \\
-\frac{2 D}{2 D} & 0 & 0 \\
0 & 0 & 0 \\
0 & 0 & 0
\end{array}\right] \cdot\left[\begin{array}{l}
V_{d} \\
V_{q} \\
V_{f}
\end{array}\right]}
\end{aligned}
$$

It should be noted that the excitation current of the rotor is difficult to measure, because all electrical components are mounted together and very difficult to access. However, the field current can be determined from the measurement of the current in the exciter. With this in mind, in a very easy way it can be concluded that there is a constant gain (profit) current $K_{I}$ which will assess the two excitation currents $\left(I_{f}, I_{e x}\right)$ and it can be written as follows

$$
I_{f}=K_{I} I_{e x}
$$

This mathematical relationship describes the peak value of the AC generator excitation and represents a DC of generator rotor. In the analysis of power systems ASE (EPS, PES) of modern aircrafts you must take into account the variability of the mechanical turbine torque and the variability of environmental conditions in which the dynamic processes of components included in the onboard electrical network are implemented, hence the mathematical equations presented in discrete form. Therefore, a full numerical model in the space of the generator is reduced to the five states instead of six.

These matrices are as follows [13], [14], [15]

$$
\begin{aligned}
& {\left[\begin{array}{c}
I_{\frac{d}{k}} \\
I \frac{q}{k} \\
\omega_{k} \\
T_{\frac{L}{k}} \\
\theta_{k}
\end{array}\right]} \\
& =\left[\begin{array}{ccccc}
1-T_{s} \frac{R_{s}}{L_{d}} & T_{s} L_{q} \frac{\omega_{k-1}}{L_{d}} & 0 & 0 & 0 \\
-T_{s} L_{d} \frac{\omega_{k-1}}{L_{q}} & 1-T_{s} \frac{R_{s}}{L_{q}} & 3 p^{2} T_{s} M_{s f} K_{i} \frac{I \frac{e x}{k-1}}{2 J} & 0 & 0 \\
3 p^{2} T_{s}\left(L_{d}-L_{q}\right) \frac{I \frac{q}{k-1}}{2 J} & -T_{s} M_{s f} K_{i} \frac{I \frac{e x}{k-1}}{L_{q}} & 1-\frac{T_{s} f}{J} & p \frac{T_{s}}{J} & 0 \\
0 & 0 & 0 & 1 & 0 \\
0 & 0 & T_{s} & 0 & 1
\end{array}\right] \\
& \cdot\left[\begin{array}{c}
I_{d}-1 \\
\frac{I_{q}}{k}-1 \\
\omega_{k-1} \\
T_{\frac{L}{k}-1} \\
\theta_{k-1}
\end{array}\right]+\left[\begin{array}{cc}
\frac{T_{s}}{L_{d t}} & 0 \\
0 & \frac{T_{s}}{L_{q t}} \\
0 & 0 \\
0 & 0 \\
0 & 0
\end{array}\right] \cdot\left[\begin{array}{c}
\frac{d}{k-1} \\
\frac{q}{k-1}
\end{array}\right]
\end{aligned}
$$

\begin{tabular}{|c|c|c|c|}
\hline$k / k-1$ & predicted quantity & $\mathrm{L}_{\mathrm{c}}$ & leakage inductance \\
\hline$k / k$ & $\begin{array}{l}\text { estimated optimal } \\
\text { quantity }\end{array}$ & M & mutual stator/rotor \\
\hline$d, q$ & $\begin{array}{l}\text { synchronous reference } \\
\text { frame index }\end{array}$ & $\psi$ & flux \\
\hline$s$ & stator quantities & $\mathrm{K}_{\text {sat }}$ & saturation coefficient \\
\hline$f$ & rotor quantities & $\mathrm{K}_{\mathrm{i}}$ & $\begin{array}{l}\text { current gain between } \mathrm{I}_{\mathrm{ex}} \\
\text { and } \mathrm{I}_{\mathrm{f}}\end{array}$ \\
\hline$V$ & voltage & $\mathrm{T}_{1}$ & load torque \\
\hline $\mathrm{V}_{\mathrm{dc}}$ & DC voltage source & $\mathrm{T}_{\mathrm{e}}$ & electromagnetic torque \\
\hline$V_{Z S S n}$ & zero sequence voltage & $\theta$ & electrical position \\
\hline I & current & $\omega$ & $\begin{array}{c}\text { electrical angular rotor } \\
\text { speed }[\mathrm{rad} / \mathrm{s}]\end{array}$ \\
\hline $\mathrm{I}_{\mathrm{ex}}$ & $\begin{array}{l}\text { exciter excitation } \\
\text { current }\end{array}$ & $\mathrm{J}$ & inertia \\
\hline $\mathrm{I}_{\mathrm{f}}$ & $\begin{array}{c}\text { main } \mathrm{S} / \mathrm{G} \text { excitation } \\
\text { current }\end{array}$ & $\mathrm{p}$ & main $S / G$ poles pairs \\
\hline $\mathrm{I}_{\mathrm{m}}$ & magnetising current & $\mathrm{N}$ & mechanical speed [rpm] \\
\hline $\mathrm{R}$ & resistor & $\mathrm{T}_{\mathrm{s}}$ & sampling period \\
\hline $\mathrm{L}$ & self-inductance & $\mathrm{L}_{\mathrm{m}}$ & magnetising inductance \\
\hline
\end{tabular}

and $T_{s}$ is the sampling period.

Table 1. Symbols used in mathematical considerations

\section{Simulation of selected components of the EPS system according to the trend of MEA/AEA}

At the beginning of the results of calculations we prepared a draft outline of the simulation model (Fig. 4). Presented earlier mathematical model was moved to the package of simulation program, which is the programming environment Matlab/Simulink. In the process of schema design of individual blocks the following assumptions were used presented in the Table 2. 
Table 2. Main Starter/Generator parameters $200 \mathrm{kVA}, 230 \mathrm{~V}, 300 \mathrm{~A}$. $400 \mathrm{~Hz}$, three phases, Y connection, three pole pairs

\begin{tabular}{|c|c|}
\hline Stator resistance & Rotor resistance \\
\hline$R_{s}=0.015 \mathrm{~V}$ & $R_{r}=0.41 \mathrm{~V}$ \\
\hline$D$ axis stator inductance & mutual inductance \\
\hline$L_{d}=0.50 \mathrm{H}$ & $M_{s f}=0.0037 \mathrm{H}$ \\
\hline$q$ axis stator inductance & nominal stator current \\
\hline$L_{q}=0.34 \mathrm{H}$ & $I_{s n}=300 \mathrm{~A}$ \\
\hline
\end{tabular}

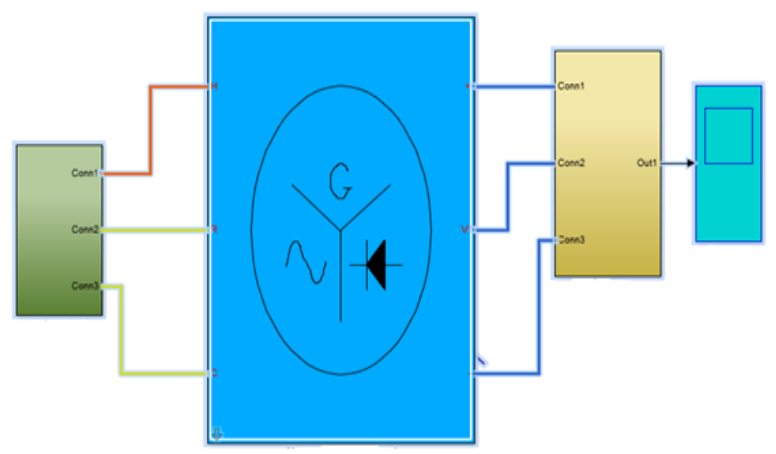

Fig. 4. The model of PMSM generator made in Matlab/Simulink

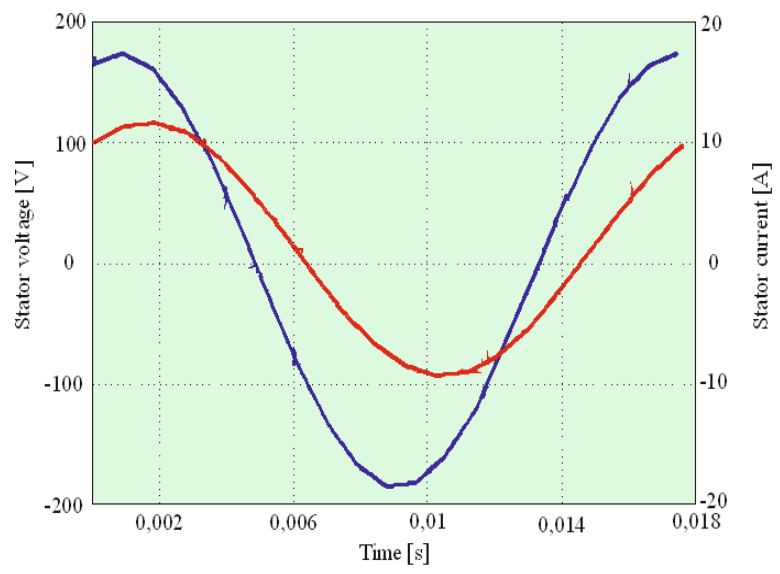

Fig. 5. The course of one cycle of the voltage and current AC on the stator

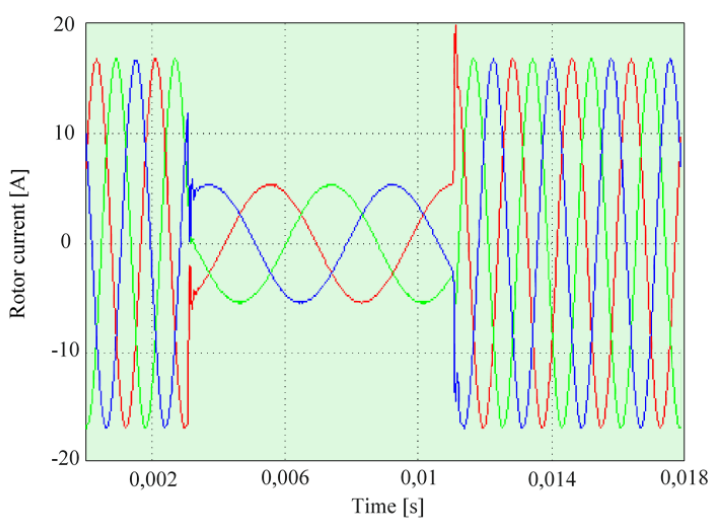

Fig. 6. Waveforms of 3-phase AC on the generator rotor

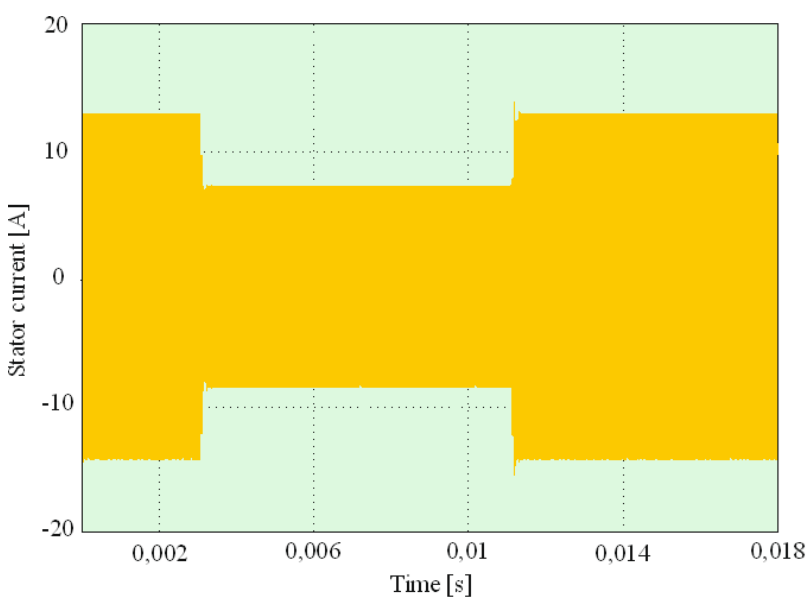

Fig. 7. Waveforms of 3-phase AC on the generator stator

It should be noted that the above voltage and current waveforms on the stator element of the generator (Fig. 5) supplied with a 3-phase voltage and current are distorted due to noise of electrical disturbances occurring in a generator and the temperature of the working environment of the device. There was also a significant variation of the amplitude signals and phase angle value for both voltages as well as AC. In turn, the waveform of 3-phase AC generator on the rotor (Fig. 6) are offset from each other by the same phase angle and have the same amplitude value and the period of repetition. Similarly, the situation is in the analysis of waveforms of three-phase $\mathrm{AC}$ on the generator stator (Fig. 7) [16], [17].

\section{Conclusions}

The article presents a study on the generator in terms of EPS system and mathematical modeling of electrical phenomena occurring in the production/processing of electricity in the airplane. The main study involved assessing the performance of the generator PMSM, supplied voltage and three-phase AC. The authors are deeply convinced that in the article solution to supply more electric aircraft will provide greater efficiency in comparison with "conventional" airplanes, equipped with a standard electrical network. The results of research, both on the basis of this mathematical model, as well as in the case of a simulation model showed that the assumed structural changes in the construction of the generator system were correct. First of all, they offer the possibility of obtaining suitably low value of AC voltage. Waveforms of harmonic currents in the induced voltage of the generator on the test rotor are defined by the current gain factor $K_{i}$. In addition, closer to the sine wave shape of the voltage can be obtained when the permanent magnets are arranged inside the rotor laminations.

Presented in the paper analysis of synchronous generator model with permanent magnets PMSM to increase the frequency of the generated voltage is to be an alternative mainly for generator sets, consisting of high-speed generators cooperating with emergency and low-efficient gearboxes and low-speed generators with a very large 
outer diameter of the stator. In every of these cases the new generator would get not worse efficiency, respectively high service life, lower weight and more compact unit structure (primarily in the case of a generator with a large number of poles).

\section{References}

1. Moir I., Seabridge A., Design and Development of Aircraft Systems, Second Edition, John Wiley \& Sons, Ltd., 2013.

2. Setlak L., Kowalik R., Mathematical modeling and simulation of selected components on-board autonomous power supply system (ASE), in accordance with the concept of a more electric aircraft (MEA), 2017 18th International Scientific Conference on Electric Power Engineering, Kouty nad Desnou, Czech Republic, pp. 1-6, IEEE 2017.

3. Parker R., Horizon 2020 Industrial Technologies as an Engine of Growth, Rolls-Royce, Presentation 2012.

4. Emandi K., Ehsani M., Aircraft power systems: technology, state of the art, and future trends, Aerospace and Electronic Systems, IEEE, 2000.

5. Krause P.C., Wasynczuk O., Sudhoff S.D., Analysis of Electrical Machinery and Drive Systems, IEEE Press, John Wiley \& Sons, Inc., 2002.

6. Setlak L., Kowalik R., Comparative Analysis and Simulation of selected Components of Modern Onboard Autonomous Power Systems (ASE) of Modern Aircraft in line with the Concept of MEA/AEA, Lecture Notes in Engineering and Computer Science, Volume 1, 2016.

7. Yang Z., Qu J., Ma J., and Shi X., Modeling and Simulation of Power Distribution System in More Electric Aircraft, Hindawi Publishing Corporation Journal of Electrical and Computer Engineering Volume, Article ID 847624, 7 pages, 2015.

8. Abdel-Fadil R., Eid A., Abdel-Salam M., Electrical distribution power systems of modern civil aircrafts, 2nd International Conference on Energy Systems and Technologies, Cairo, Egypt 2013.

9. Singh B., Murthy S.S., and Gupta S., Analysis and design of STATCOM-based voltage regulator for self-excited induction generators, IEEE Trans. Energy Convers., vol. 19, no. 4, pp. 783-790, Dec, 2004.

10. Zhao X., Guererro J.M., Wu X., Review of Aircraft Electric Power Systems and Architectures, International Energy Conference (ENERGYCON), IEEE 2014.

11. Skvarenina T.L., Pekarek S., Wasynczuk O., and Krause P.C., Simulation of a More-Electric Aircraft Power System using an automated state model approach, Proceedings of the Intersociety Energy Conversion Engineering Conference, pp. 133-136, 1996.

12. Cheng R., Zhao W., Deng H., and Jiang X., Modeling and Optimization Control for Aircraft AC Generator Brushless Excitation System Based on Improved Adaptive PSO, The Open Automation and Control Systems Journal, vol. 7, 21-30, 2015.

13. Fernando W.U.N., Barnes M., and Marjanovic O., Direct drive permanent magnets generator fed ACDC active rectification and control for moreelectric aircraft engines, IET Electric Power Applications, vol. 5, no. 1, pp. 14-27, Jan. 2011.

14. Vadher Vinod Vashram, Mathematical Modelling of Aircraft Electrical Power Systems, Doctoral Thesis, Loughborough University of Technology, 1981.

15. Maalouf A., Idkhajine L., Le Ballois S., Monmasson E., Field programmable gate arraybased sensorless control of a brushless synchronous starter generator for aircraft application, Published in IET Electric Power Applications, 2010.

16. Burrow S.G., Mellor P.H., Churn P., Sawata T., and Holme M., Sensorless operation of a permanent-magnet generator for aircraft, IEEE Trans. Industry Applications, vol. 44, no. 1, pp. 101-107, Jan./Feb. 2008.

17. Setlak L., Overview of Aircraft Technology solutions compatible with the concept of MEA, Technical Transactions. Electrical Engineering, No. 1-E/2015, p. 67-76, Cracow University of Technology 2015 . 